\title{
Diets containing traditional and novel green leafy vegetables improve liver fatty acid profiles of spontaneously hypertensive rats
}

\author{
Melissa Johnson ${ }^{1}$, Ralphenia D Pace ${ }^{2}$, Norma L Dawkins ${ }^{2}$ and Kyle R Willian ${ }^{3^{*}}$
}

\begin{abstract}
Background: The consumption of green leafy vegetables (GLVs) has been demonstrated to reduce the risks associated with cardiovascular and other diseases. However, no literature exists that examines the influence of traditional and novel GLVs on the liver fatty acid profile of an animal model genetically predisposed to developing hypertension. The aim of the present study was to examine the effects of diets containing $4 \%$ collard greens, purslane or sweet potato greens on the liver fatty acid profiles of four-week old male spontaneously hypertensive rats (SHRs, $N=44$ ). Following four weeks consumption of the diets, liver fatty acid profiles were determined by gasliquid chromatography of transesterified fatty acid methyl esters.

Results: SHRs consuming the control diet had greater percentages of liver saturated fatty acid and less omega-3 fatty acid percentages. SHRs consuming the diets containing vegetables had significantly greater liver concentrations of $\gamma$ - linolenic, docosahexaenoic and docosahexaenoic acids, as well as lower levels of lauric, palmitic and arachidonic acids. SHRs consuming the control diet had significantly greater percentages $(p<0.05)$ of oleic; significantly less $\gamma$-linolenic and docosahexaenoic acids.

Conclusions: This study demonstrates the ability of GLVS to modulate liver fatty acid composition, thus providing protection against elevations in atherogenic fatty acids, which may be involved in CVD pathogenesis. Consequently, dietary recommendations for the prevention of CVD should consider the possible cardioprotective benefits and the subsequent alterations in fatty acid profiles afforded by diets containing collard greens, purslane and sweet potato greens.
\end{abstract}

\section{Background}

Cardiovascular disease (CVD) is the leading cause of morbidity and mortality in the US as well as developing nations [1]. In addition to genetic predisposition, risk factors for CVD include atherogenic dietary patterns affluent in processed food products, total fat, saturated fat, cholesterol, refined carbohydrates and sodium and inadequate intakes of whole grain products, fruits, vegetables and dietary fiber [2-5].

Plants, particularly green leafy vegetables (GLVs), serve as a major dietary reservoir of the essential PUFAs, dietary fiber, antioxidants and other bioactive compounds that exert cardioprotective and chemopreventive biological

\footnotetext{
* Correspondence: krw0018@auburn.edu

${ }^{3}$ Department of Chemistry and Biochemistry, Auburn University, Auburn, AL 36849-5312, USA

Full list of author information is available at the end of the article
}

mechanisms [6-9]. Epidemiological studies have revealed that consumption of fruits and vegetables may be inversely associated with risk for CVD and certain cancers, with the prevalence of disease much lower among individuals consuming near or above the recommended servings compared to those consuming fewer than the recommended intakes [10-12].

Collard greens (Brassica oleracea), a traditional GLV consumed mainly in the southern region of the United States, in addition to purslane (Portulaca oleracea) and sweet potato greens (Ipomoea batatas L.), novel GLVs to the typical American diet, may prove beneficial in reducing the risks associated with CVD development and progression [13-17]. Research has demonstrated reductions in CVD risk following consumption of these green leafy vegetables, both in vivo and in vitro [18-22]. Although epidemiological evidence has affirmed the association 
between GLV consumption and reductions in disease risk, there is limited research examining the effects of diets containing collard greens (CG), purslane (PL) and sweet potato greens (SPG) on cardiovascular disease risk, namely liver fatty acid profiles. To test the hypothesis that diets containing CG, PL and SPG (4\% dry weight) will contribute to improvements in liver fatty acid profiles the present study was designed to determine the effects of diets containing these GLVs on the liver fatty acid profile of animals genetically predisposed to developing hypertension, the spontaneously hypertensive rat. This study will advance human nutrition research with inferences made regarding the effects of consumption of traditional and novel GLVs on CVD risk factors. Additionally, further recommendations regarding supplementation of these GLVs into the diet on CVD risk may be presented.

\section{Results}

\section{Liver saturated fatty acids}

Liver saturated fatty acid concentrations of SHRs consuming the various diets are presented in Table 1. SHRs consuming the control diet had trace amounts of lauric acid $(\mathrm{C} 12: 0)$ that was significantly $(\mathrm{P}<0.05)$ greater than those consuming the experimental diets. Significantly greater amounts of pentadecanoic acid (C15:0) were present in the livers of SHRs consuming PL diet $(0.09 \pm 0.01)$ in comparison to those consuming the SPG $\operatorname{diet}(0.06 \pm 0.01)$.

\section{Liver monounsaturated fatty acids}

SHRs consuming diets containing CG, PL and SPG exhibited significantly lower liver concentrations of palmitoleic $(\mathrm{C} 16: 1 \mathrm{n} 7)$ acid $(0.78 \pm 0.19,0.90 \pm 0.14,0.12 \pm$ 0.02 , respectively) than those consuming the control diet $(1.42 \pm 0.06)$. Liver oleic acid $(\mathrm{C} 18: 1 \mathrm{n} 9)$ was significantly increased following 4 weeks consumption of the control diet $(12.69 \pm 1.03)$. Among SHRs consuming diets containing GLVs, oleic acid concentration was greater with consumption of the PL diet $(7.70 \pm 1.14)$, followed by the CG $(7.40 \pm 1.95)$ and SPG $(5.57 \pm 1.16)$ diets. A more than two-fold significant increase in eicosenoic acid (C20:1n12) was present among SHRs assigned to the PL dietary group $(0.28 \pm 0.00)$ in comparison to those assigned to the control group $(0.12 \pm 0.03)$ (Table 2$)$.

\section{Liver polyunsaturated fatty acids}

SHRs in the control group exhibited significantly lower amounts of $\gamma$-linolenic (GLA, C18:3n6) and docosahexaenoic (DHA, C22:6n3) acids versus those consuming the experimental diets containing GLVs (Table 3). GLA percentages ranged from $0.93 \pm 0.49$ (control) to $5.59 \pm$ 0.73 (PL); DHA percentages ranged from $5.16 \pm 0.35$ (control) to $8.53 \pm 0.63$ (SPG). Significantly less docosatrienoic acid (C22:3n3) was present following the consumption of the PL diet $(0.60 \pm 0.11)$ versus the control diet $(1.01 \pm 0.07)$. A significantly greater amount of docosahexaenoic acid (C22:6n3) was present following the consumption of the experimental diets containing CG $(8.31 \pm 1.27)$, PL $(8.44 \pm 1.02)$ and SPG $(8.53 \pm 0.63)$ in comparison to the control diet $(5.16 \pm 0.35)$.

\section{Liver total fatty acids}

Although not statistically significant, SHRs consuming the control diet exhibited a greater percentage of liver total saturated fatty acids [23] (39.68 \pm 1.51$)$ and a lesser percentage of total unsaturated fatty acids (UFA; $62.18 \pm$ 1.22) (Table 4). SHRs consuming the experimental diets

Table 1 Liver saturated fatty acid concentrations of SHRs fed diets for 4 weeks ${ }^{\S}$

\begin{tabular}{|c|c|c|c|c|c|}
\hline \multirow[b]{2}{*}{ Fatty acid } & \multirow[b]{2}{*}{ Structure } & \multicolumn{4}{|c|}{ Dietary group } \\
\hline & & Control & $4 \%$ CG & $4 \% \mathrm{PL}$ & $4 \%$ SPG \\
\hline Capric & C10:0 & nd & nd & nd & nd \\
\hline Undecylic & C11:0 & nd & nd & nd & nd \\
\hline Lauric & C12:0 & $0.01 \pm 0.00^{\mathrm{a}}$ & $0.00 \pm 0.00^{b}$ & $0.00 \pm 0.00^{b}$ & $0.00 \pm 0.00^{b}$ \\
\hline Tridecylic & C13:0 & $1.60 \pm 0.43^{\mathrm{a}}$ & $1.12 \pm 0.25^{\mathrm{a}}$ & $1.02 \pm 0.39^{\mathrm{a}}$ & $1.33 \pm 0.30^{a}$ \\
\hline Myristic & C14:0 & $0.29 \pm 0.04^{\mathrm{a}}$ & $0.29 \pm 0.06^{a}$ & $0.29 \pm 0.05^{\mathrm{a}}$ & $0.26 \pm 0.06^{a}$ \\
\hline Pentadecanoic & C15:0 & $0.07 \pm 0.01^{\mathrm{ab}}$ & $0.08 \pm 0.01^{\mathrm{ab}}$ & $0.09 \pm 0.01^{\mathrm{a}}$ & $0.06 \pm 0.01^{b}$ \\
\hline Palmitic & C16:0 & $21.01 \pm 0.70^{a}$ & $18.44 \pm 4.24^{\mathrm{a}}$ & $19.47 \pm 2.67^{\mathrm{a}}$ & $16.95 \pm 3.07^{\mathrm{a}}$ \\
\hline Heptadecanoic & C17:0 & $0.27 \pm 0.13^{\mathrm{a}}$ & $0.64 \pm 0.32^{\mathrm{a}}$ & $0.78 \pm 0.27^{a}$ & $0.88 \pm 0.38^{a}$ \\
\hline Stearic & C18:0 & $16.30 \pm 0.71^{\mathrm{a}}$ & $20.71 \pm 4.60^{\mathrm{a}}$ & $17.45 \pm 2.53^{\mathrm{a}}$ & $18.31 \pm 2.53^{\mathrm{a}}$ \\
\hline Arachidic & C20:0 & $0.08 \pm 0.04^{a}$ & $0.04 \pm 0.00^{\mathrm{a}}$ & nd & $0.05 \pm 0.00^{a}$ \\
\hline Behenic & C22:0 & $0.11 \pm 0.02^{\mathrm{a}}$ & $0.31 \pm 0.08^{\mathrm{a}}$ & $0.39 \pm 0.15^{\mathrm{a}}$ & $0.40 \pm 0.09^{\mathrm{a}}$ \\
\hline Lignoceric & C24:0 & $0.41 \pm 0.16^{a}$ & $0.59 \pm 0.24^{\mathrm{a}}$ & $1.23 \pm 1.05^{\mathrm{a}}$ & $0.62 \pm 0.38^{a}$ \\
\hline
\end{tabular}

${ }^{5}$ Data are (expressed as) mean percentage \pm SE. Values in the same row that do not share the same superscript letter are significantly different according to analysis of variance and Duncan's post hoc procedures $(P<.05) ;$ nd $=$ not detected.

Control $=$ AIN-76 A control diet; $4 \%$ CG $=$ AIN-76A diet $+4 \%$ collard green powder; $4 \%$ purslane $=$ AIN-76A diet $+4 \%$ purslane powder; $4 \%$ SPG $=$ AIN-76A diet $+4 \%$ sweet potato green powder. 
Table 2 Liver monounsaturated fatty acid concentrations of SHRs fed diets for 4 weeks ${ }^{\S}$

\begin{tabular}{|c|c|c|c|c|c|}
\hline \multirow[b]{2}{*}{ Fatty acid } & \multirow[b]{2}{*}{ Structure } & \multicolumn{4}{|c|}{ Dietary group } \\
\hline & & Control & $4 \%$ CG & $4 \% \mathrm{PL}$ & $4 \%$ SPG \\
\hline Pentadecenoic & $\mathrm{C} 15: 1 \mathrm{n} 5 \mathrm{c}$ & $0.09 \pm 0.02^{a}$ & $0.04 \pm 0.00^{a}$ & $0.02 \pm 0.00^{a}$ & $0.05 \pm 0.00^{a}$ \\
\hline Palmitelaidic & $\mathrm{C} 16: 1 \mathrm{t}$ & $0.18 \pm 0.03^{\mathrm{a}}$ & $0.14 \pm 0.02^{\mathrm{a}}$ & $0.15 \pm 0.03^{a}$ & $0.12 \pm 0.02^{a}$ \\
\hline Palmitoleic & C16:1n7 & $1.42 \pm 0.06^{\mathrm{a}}$ & $0.78 \pm 0.19^{b}$ & $0.90 \pm 0.14^{b}$ & $0.74 \pm 0.15^{b}$ \\
\hline Heptadecenoic & C17:1n7 & $0.04 \pm 0.01^{\mathrm{a}}$ & $1.56 \pm 1.53^{\mathrm{a}}$ & $0.07 \pm 0.03^{\mathrm{a}}$ & $0.03 \pm 0.01^{a}$ \\
\hline Cis-vaccenic & $\mathrm{C} 18: 1 \mathrm{n} 7 \mathrm{c}$ & $3.36 \pm 0.61^{a}$ & $2.05 \pm 0.31^{a}$ & $2.20 \pm 0.10^{a}$ & $2.33 \pm 0.12^{\mathrm{a}}$ \\
\hline Elaidic & C18:1n9t & $1.90 \pm 0.21^{\mathrm{a}}$ & $5.95 \pm 4.11^{a}$ & $1.53 \pm 1.43^{\mathrm{a}}$ & $2.49 \pm 2.45^{a}$ \\
\hline Oleic & C18:1n9c & $12.69 \pm 1.03^{\mathrm{a}}$ & $7.40 \pm 1.95^{b}$ & $7.70 \pm 1.14^{b}$ & $5.57 \pm 1.16^{b}$ \\
\hline Trans-vaccenic & C18:1n11 & $1.82 \pm 0.00^{\mathrm{a}}$ & $0.16 \pm 0.09^{a}$ & $0.65 \pm 0.41^{a}$ & $1.42 \pm 0.00^{\mathrm{a}}$ \\
\hline Eicosenoic & C20:1n12 & $0.12 \pm 0.03^{\mathrm{a}}$ & $0.16 \pm 0.01^{\mathrm{ab}}$ & $0.28 \pm 0.00^{b}$ & $0.16 \pm 0.06^{\mathrm{ab}}$ \\
\hline
\end{tabular}

${ }^{\S}$ Data are (expressed as) mean percentage \pm SE. Values in the same row that do not share the same superscript letter are significantly different according to analysis of variance and Duncan's post hoc procedures $(P<.05)$; nd = not detected.

Control $=$ AIN-76 A control diet; 4\% CG $=$ AIN-76A diet $+4 \%$ collard green powder; $4 \%$ purslane $=$ AIN-76A diet $+4 \%$ purslane powder; $4 \%$ SPG $=$ AIN-76A diet $+4 \%$ sweet potato green powder.

Values in rows with multiple superscript letters (e.g. ab) are not significantly different from other values containing the shared superscript letter (e.g. a or b).

containing CG, PL and SPG demonstrated greater percentages of omega-3 fatty acids $(7.88 \pm 1.16,7.67 \pm 1.38$, $8.62 \pm 0.64$, respectively) in comparison to those consuming the control diet ( $5.27 \pm 0.34)$. Omega- 3 fatty acid percentages, as well as EPA + DHA percentages were significantly greater following consumption of the SPG diet than the control diet.

\section{Discussion}

Green leafy vegetables such as collard greens, traditionally consumed in the southern region of the US, purslane and sweet potato greens, relatively novel in the American diet, which are rich sources of antioxidants, MUFA, PUFAs and $n-3$ series PUFAs have demonstrated the ability to attenuate the risks associated with disease pathogenesis [24-29]. In the present study experimental diets containing these GLVs were able to contribute to increased SHR liver concentrations of cardio-protective omega-3 polyunsaturated fatty acids compared to the control diet. Medeiros et al. demonstrated the ability of diets enriched with the omega-3 fatty acid ALA to significantly increase the omega-3 fatty acid (i.e. DHA) content of the

Table 3 Liver polyunsaturated fatty acid concentrations of SHRs fed diets for 4 weeks $\$$

\begin{tabular}{|c|c|c|c|c|c|}
\hline \multirow[b]{2}{*}{ Fatty acid } & \multirow[b]{2}{*}{ Structure } & \multicolumn{4}{|c|}{ Dietary group } \\
\hline & & Control & $4 \%$ CG & $4 \% \mathrm{PL}$ & $4 \%$ SPG \\
\hline Linolelaidic & $C 18: 2 n 6 t$ & $0.49 \pm 0.19^{a}$ & $0.09 \pm 0.01^{\mathrm{a}}$ & $0.17 \pm 0.05^{a}$ & $0.32 \pm 0.27^{\mathrm{a}}$ \\
\hline Linoleic & C18:2n6c & $14.07 \pm 0.68^{\mathrm{a}}$ & $16.44 \pm 0.01^{\mathrm{a}}$ & $16.45 \pm 2.78^{\mathrm{a}}$ & $16.56 \pm 2.82^{\mathrm{a}}$ \\
\hline a-Linolenic & C18:3n3 & $0.10 \pm 0.01^{\mathrm{a}}$ & $0.10 \pm 0.02^{a}$ & $0.10 \pm 0.01^{\mathrm{a}}$ & $0.07 \pm 0.02^{a}$ \\
\hline Y-Linolenic & C18:3n6 & $0.93 \pm 0.49^{a}$ & $3.70 \pm 0.18^{b}$ & $5.59 \pm 0.73^{b}$ & $3.55 \pm 1.20^{b}$ \\
\hline Eicosadienoic & $C 20: 2 n 6$ & $0.34 \pm 0.04^{a}$ & $0.27 \pm 0.06^{\mathrm{a}}$ & $0.39 \pm 0.09^{\mathrm{a}}$ & $0.23 \pm 0.04^{a}$ \\
\hline Eicosatrienoic & $C 20: 3 n 3$ & $0.09 \pm 0.02^{a}$ & $0.27 \pm 0.14^{\mathrm{a}}$ & $0.18 \pm 0.10^{\mathrm{a}}$ & $0.26 \pm 0.15^{a}$ \\
\hline Dihomo- $\gamma$-linolenic & $C 20: 3 n 6$ & $0.32 \pm 0.02^{a}$ & $0.31 \pm 0.04^{a}$ & $0.44 \pm 0.03^{b}$ & $0.37 \pm 0.02^{\mathrm{ab}}$ \\
\hline Arachidonic & $C 20: 4 n 6$ & $20.39 \pm 1.27^{\mathrm{a}}$ & $14.15 \pm 3.44^{a}$ & $15.80 \pm 3.16^{a}$ & $18.51 \pm 3.58^{\mathrm{a}}$ \\
\hline Eicosapentaenoic & $C 20: 5 n 3$ & $0.10 \pm 0.02^{a}$ & $0.10 \pm 0.01^{\mathrm{a}}$ & $0.19 \pm 0.06^{a}$ & $0.10 \pm 0.01^{a}$ \\
\hline Docosadienoic & $\mathrm{C} 22: 2 \mathrm{n} 6$ & $0.03 \pm 0.02^{a}$ & $4.09 \pm 4.04^{\mathrm{a}}$ & $0.09 \pm 0.04^{\mathrm{a}}$ & $0.07 \pm 0.04^{a}$ \\
\hline Docosatrienoic & $C 22: 3 n 3$ & $1.01 \pm 0.07^{\mathrm{a}}$ & $0.76 \pm 0.09^{\mathrm{ab}}$ & $0.60 \pm 0.11^{b}$ & $0.87 \pm 0.11^{\mathrm{ab}}$ \\
\hline Docosatatraenoic & $C 22: 4 n 6$ & $0.68 \pm 0.04^{a}$ & $0.64 \pm 0.08^{a}$ & $0.78 \pm 0.11^{a}$ & $0.85 \pm 0.10^{a}$ \\
\hline Docosapentaenoic & $C 22: 5 n 3$ & $1.95 \pm 0.42^{\mathrm{a}}$ & $2.98 \pm 0.73^{a}$ & $2.34 \pm 0.34^{a}$ & $1.72 \pm 0.19^{\mathrm{a}}$ \\
\hline Docosahexaenoic & C22:6n3 & $5.16 \pm 0.35^{\mathrm{a}}$ & $8.31 \pm 1.27^{b}$ & $8.44 \pm 1.02^{b}$ & $8.53 \pm 0.63^{b}$ \\
\hline
\end{tabular}

${ }^{\S}$ Data are (expressed as) mean percentage \pm SE. Values in the same row that do not share the same superscript letter are significantly different according to analysis of variance and Duncan's post hoc procedures $(\mathrm{P}<.05) ; \mathrm{nd}=$ not detected. Control $=\mathrm{AIN}-76 \mathrm{~A}$ control diet; $4 \% \mathrm{CG}=\mathrm{AIN}-76 \mathrm{~A}$ diet $+4 \%$ collard green powder; $4 \%$ purslane $=$ AIN-76A diet $+4 \%$ purslane powder; $4 \%$ SPG $=$ AIN-76A diet $+4 \%$ sweet potato green powder

Values in rows with multiple superscript letters (e.g. ab) are not significantly different from other values containing the shared superscript letter (e.g. a or b). 
Table 4 Total liver fatty acid concentrations and ratios of SHRs fed diets for 4 weeks $\$$

\begin{tabular}{|c|c|c|c|c|}
\hline \multirow[b]{2}{*}{ Fatty acid } & \multicolumn{4}{|c|}{ Dietary group } \\
\hline & Control & $4 \%$ CG & $4 \% \mathrm{PL}$ & $4 \%$ SPG \\
\hline Saturated & $39.68 \pm 1.51^{a}$ & $33.99 \pm 7.63^{a}$ & $32.57 \pm 5.91^{a}$ & $33.16 \pm 5.64^{a}$ \\
\hline Unsaturated & $62.18 \pm 1.22^{\mathrm{a}}$ & $67.64 \pm 7.52^{a}$ & $67.84 \pm 5.81^{a}$ & $68.97 \pm 5.03^{\mathrm{a}}$ \\
\hline Monounsaturated & $18.25 \pm 1.51^{\mathrm{a}}$ & $20.22 \pm 4.58^{a}$ & $22.14 \pm 5.09^{a}$ & $20.17 \pm 4.43^{\mathrm{a}}$ \\
\hline Polyunsaturated & $43.92 \pm 1.51^{\mathrm{a}}$ & $47.42 \pm 6.27^{a}$ & $45.70 \pm 1.89^{a}$ & $48.80 \pm 1.04^{\mathrm{a}}$ \\
\hline Omega-3 fatty acids & $5.27 \pm 0.34^{a}$ & $7.88 \pm 1.16^{\mathrm{ab}}$ & $7.67 \pm 1.38^{\mathrm{ab}}$ & $8.62 \pm 0.64^{b}$ \\
\hline Omega- 6 fatty acids & $34.47 \pm 1.47^{\mathrm{a}}$ & $32.25 \pm 2.15^{a}$ & $30.59 \pm 3.06^{\mathrm{a}}$ & $35.07 \pm 1.05^{\mathrm{a}}$ \\
\hline Omega- $6 / 3$ ratio & $6.68 \pm 0.23^{\mathrm{a}}$ & $9.05 \pm 4.97^{\mathrm{a}}$ & $8.17 \pm 4.87^{a}$ & $4.31 \pm 0.33^{a}$ \\
\hline LA/ALA ratio & $14.13 \pm 1.51^{a}$ & $11.95 \pm 1.89^{\mathrm{a}}$ & $12.17 \pm 1.89^{\mathrm{a}}$ & $17.48 \pm 3.44^{\mathrm{a}}$ \\
\hline$E P A+D H A$ & $5.20 \pm 0.34^{a}$ & $7.82 \pm 1.17^{\mathrm{ab}}$ & $7.62 \pm 1.38^{\mathrm{ab}}$ & $8.59 \pm 0.65^{b}$ \\
\hline
\end{tabular}

${ }^{5}$ Data are (expressed as) mean percentage \pm SE. Values in the same row that do not share the same superscript letter are significantly different according to analysis of variance and Duncan's post hoc procedures $(\mathrm{P}<.05)$; nd = not detected. Control = AIN-76 A control diet; $4 \%$ CG $=$ AIN-76A diet $+4 \%$ collard green powder; $4 \%$ purslane $=\mathrm{AIN}-76 \mathrm{~A}$ diet $+4 \%$ purslane powder; $4 \% \mathrm{SPG}=\mathrm{AIN}-76 \mathrm{~A}$ diet $+4 \%$ sweet potato green powder.

Saturated = sum of saturated fatty acids; unsaturated = sum monounsaturated fatty acids + sum polyunsaturated fatty acids); monounsaturated = sum of monounsaturated fatty acids; polyunsaturated = sum of polyunsaturated fatty acids; omega-3 fatty acids = sum of C18:3n3, C20:5n3 and C22:5n3; omega- 6 fatty acids = sum of C18:2n6 and C20:4n6; omega-6/3 ratio = omega-6/omega-3 fatty acids; LA/ALA ratio = C18:2n6 (linoleic acid, LA)/C18:3n3 (a-linolenic acid, ALA); EPA $+\mathrm{DHA}=$ sum of C20:5n3 (eicosapentaenoic acid, EPA) and C22:6n3 (docosahexaenoic acid, DHA).

Values in rows with multiple superscript letters (e.g. ab) are not significantly different from other values containing the shared superscript letter (e.g. a or b).

rat liver [30]. Although percentages of liver ALA were similar among SHRs consuming the different diets in the present study, greater percentages of DHA were observed among those consuming the diets containing the GLVs; SHRs consuming the PL diet exhibited a greater percentage of EPA compared to those in the other dietary groups. Interestingly, although ALA content was slightly less in the livers of SHRs consuming the SPG diet, DHA content was greater in comparison to those consuming the other diets. Greater percentages of omega- 3 fatty acids within the livers of SHRs consuming diets containing GLVs, particularly EPA and DHA, suggest potential cardioprotection and reduced disease risk as demonstrated by others [31].

Greater concentrations of omega-3 PUFAs compared to omega-6 PUFAs among SHRs consuming diets containing the GLVs implies that omega-6 PUFAs may be metabolized to a lesser extent due to the competitive nature of these PUFAs for participation in metabolic pathways. In the current study liver ALA concentrations were similar across all dietary groups, whereas LA concentrations were greater following consumption of the experimental diets containing CG, PL and SPG; liver AA concentrations were increased following consumption of the control diet. The shift towards a trajectory favoring the metabolism of ALA to a greater degree than LA, suggest the ability of diets containing GLVs to promote health and prevent disease.

The data generated from the present study examining the liver fatty acid composition of SHRs consuming diets containing traditional and novel GLVs indicate significant differences in key atherogenic as well as cardioprotective fatty acids. Research has shown an increased risk for CVD with increasing concentrations of the saturated fatty acids lauric, myristic and palmitic, which are considered to be more atherogenic [32]. In the present study, SHRs consuming the control diet demonstrated greater liver concentrations of both lauric and myristic acids. Further, higher percentages of cardioprotective fatty acids of the omega-3 series were found in the livers of SHRs fed diets containing GLVs. The presence of higher levels of these fatty acids suggest potential decreased disease risk via the cardioprotective mechanisms of omega- 3 fatty acids generated during anti-inflammatory pathways present during cardiovascular and other disease pathogenesis.

\section{Conclusions}

To our knowledge, this is the first study to examine the effects of diets containing traditional (i.e. collard greens) and novel (i.e. purslane and sweet potato greens) green leafy vegetables on the liver fatty acid profile of the spontaneously hypertensive rat. The current research findings are in agreement with epidemiological evidence, which suggests the cardioprotective and chemopreventive advantages of consuming diets containing dark green leafy vegetables. The results of this research suggest the ability of diets containing collard greens, purslane and sweet potato greens to favourable shift SHR liver fatty acid compositions in such a way that may be beneficial in reducing CVD risk in spontaneously hypertensive rats.

The chief limitation of the current study was the duration of feeding of the control and experimental diets to the spontaneously hypertensive rats. As CVD is a chronic, inflammatory disease occurring over the course of the lifespan, extending the duration of feeding may offer critical 
insights regarding long-term consumption of novel and traditional GLVs on the pathogenesis of CVD. In addition, focusing on only one aspect of CVD risk, namely the liver fatty acid profile, fails to offer a comprehensive view of the larger spectrum involved in CVD pathogenesis. Examining the effects of diets containing collard greens, purslane and sweet potato greens on factors such as the complete lipid profile, lipid and other nutrient metabolism and other relevant indices of cardiovascular health, such as cardiac hypertrophy, inflammatory biomarkers, tissue morphology, gene expression and SHR physiology, may offer critical evidence regarding the influence of these diets on disease outcomes. Further, implications and translation of the current and future studies to human nutrition and cardiovascular outcomes needs to be explored as well.

In addition, future research studies may want to consider the isolation of nutrient and bioactive compounds within these diets that may have contributed to the presence of a beneficial fatty acid profile. Accordingly, moderate to long-term feeding studies involving the consumption of these diets by SHRs, as well as the consumption of these diets by "normal" rats, not genetically predisposed to developing hypertension warrant further consideration. Therefore, confirming the relationship between shifts in liver fatty acid profile on indices of cardiovascular health or CVD disease pathogenesis, through continued research studies will add credence to the physiological relevance of the current research study.

\section{Methods}

\section{Animals and diets}

Forty-four $(\mathrm{N}=44)$ male spontaneously hypertensive rats (SHRs), approximately 4 weeks of age and weighing 100 grams were obtained from Charles River laboratories (St. Louis, MO). The animals were housed individually in stainless steel cages at the animal care wing of the Tuskegee University Comparative Medicine Research Center. Room temperature and relative humidity were maintained between 68 and $72^{\circ} \mathrm{C}$ and $55 \%$, respectively. SHRs were maintained on a 12-hour light/12-hour dark cycle.

Experimental diets (Table 5), formulated according to the American Institute of Nutrition (AIN) standards were isocaloric and isonitrogenous, and manufactured by the TestDiet ${ }^{\bullet}$ division of the Purina Mills Company (Richmond, IN). Collard greens (CG) and purslane (PL) were purchased from local farmers markets and sweet potato greens (SPG) were grown on the campus of Tuskegee University. Vegetables were washed, blotted dry and frozen for at least 24 hours prior to freeze drying for approximately 48 hours (Virtis Genesis 25SL freeze-dryer; Virtis Company, Gardiner, NY); following freeze-drying, the samples were ground to pass through a 60-mesh sieve. GLV powders were stored in an air
Table 5 Ingredient composition of control and experimental diets fed to SHRs for 4 weeks

\begin{tabular}{lcccc}
\hline & \multicolumn{4}{c}{ Dietary group } \\
\cline { 2 - 5 } Ingredient $\mathbf{( g / k g )}$ & Control & $\mathbf{4 \%}$ CG & $\mathbf{4 \% ~ P L}$ & $\mathbf{4 \% ~ S P G}$ \\
\hline Sucrose & 50.0 & 50.0 & 48.0 & 47.0 \\
Casein & 20.0 & 20.0 & 19.0 & 19.0 \\
Corn starch & 15.0 & 15.0 & 15.0 & 15.0 \\
Powdered cellulose & 5.0 & 2.0 & 4.0 & 5.0 \\
Corn oil & 5.0 & 5.0 & 5.0 & 5.0 \\
AlN-76 mineral mix & 3.5 & 4.0 & 4.0 & 4.0 \\
AlN-76 vitamin mix & 1.0 & 1.0 & 1.0 & 1.0 \\
DL-methionine & 0.3 & 0.3 & 0.3 & 0.3 \\
Choline bitartrate & 0.2 & 0.2 & 0.2 & 0.2 \\
Collard greens & - & 4.0 & - & - \\
Purslane & - & - & 4.0 & - \\
Sweet potato greens & - & - & - & 4.0 \\
\hline
\end{tabular}

tight container and shipped to the Purina Mills Company for incorporation into the experimental diets. Following subjection to a one week acclimation period, SHRs were randomly assigned to one of four dietary groups ( $\mathrm{n}=11$ per dietary group): AIN-76A purified diet (control), AIN-76A diet containing 4\% collard greens (CG; 4\% dry weight), AIN-76A diet containing 4\% purslane (PL; 4\% dry weight) or AIN-76A diet containing 4\% sweet potato greens (SPG; 4\% dry weight).

Animals were pair fed based on the previous day's dietary intake of the control group and allowed to consume food and water ad libitum. Following the 4-week feeding experiment, animals were fasted overnight and anaesthetized by overinhalation of carbon dioxide, followed by cardiac puncture. SHR livers were removed and stored at $-80^{\circ} \mathrm{C}$ prior to analysis. The procedures involved in the care and use of animals in this research were approved by the Tuskegee University Institutional Animal Care and Use Committee.

\section{Liver fatty acid analysis}

The extraction of total liver fatty acids was conducted using the method of Folch et al. [33]. Briefly, thawed liver tissue samples $(\sim 1 \mathrm{~g})$ were homogenized in a chloroformmethanol (2:1 vol/vol) mixture under nitrogen in an ice bath and total lipids extracted. The homogenate was filtered through Whatman No. 4 filter paper and $0.1 \mathrm{M}$ $\mathrm{NaCl}$ solution (4:1 ratio) was added to the filtered sample solution. The sample was then flushed with nitrogen, vortexed for 3 minutes and centrifuged at 2,000 rpm for 5 minutes. The organic layer was collected and dried off using a nitrogen evaporator. Extracted total lipids were then transferred into glass tubes and transmethylated by subjection to $1 \mathrm{ml}$ of boron trifluoride (12\% in methanol; 
Fisher Scientific, Fair Lawn, NJ), followed by incubation on a dry heating block at 110 to $115^{\circ} \mathrm{C}$ for 30 minutes to produce fatty acid methyl esters (FAMEs). The tube was then placed into an ice bath for 5 minutes; $2.0 \mathrm{ml}$ of pentane and $1.0 \mathrm{ml}$ of deionized water was added, the sample was flushed with nitrogen and vortexed for 15 seconds. Following centrifugation for 5 minutes at 2,000 rpm the top layer of the sample was collected and transferred into a pre-weighed $13 \times 100$ Pyrex culture tube. Dichloromethane $(\mathrm{DCM})$ was added $(3 \mathrm{~mL})$ and the sample was dried using a nitrogen evaporator. Prior to gas chromatography injection, the sample was resuspended in $200 \mu \mathrm{l}$ of DCM.

Fatty acid methyl esters were isolated and quantified by gas chromatography using a Hewlett-Packard 6890 gas chromatograph containing a fused silica capillary column (DB-23 $60.0 \mathrm{~m} \times 250 \mu \mathrm{m} \times 0.25 \mu \mathrm{m}$ ) furnished with a flame-ionization detector. A volume of $1 \mu \mathrm{L}$ of the sample was injected by the auto sampler at a 10:1 split ratio. Helium served as the carrier gas, with a flow rate of $2.0 \mathrm{~mL} / \mathrm{min}$. Injector and column temperatures were positioned at $250^{\circ} \mathrm{C}$. The initial oven temperature was $130^{\circ} \mathrm{C}$ and held for 1 minute followed by a $6.5^{\circ} \mathrm{C} / \mathrm{min}$ increment increases in temperature until a temperature of $170^{\circ} \mathrm{C}$ was achieved. The temperature was again increased at $2.75^{\circ} \mathrm{C}$ per minute until a temperature of $215^{\circ} \mathrm{C}$ was reached and maintained for 12 minutes. A final temperature of $230^{\circ} \mathrm{C}$ was reached and maintained for 3 minutes. Eluted FAMEs were identified based on comparisons to retention times and peaks of known FAMEs contained in an external standard (GLC 463 Standard, NU Check (Elysian, MN)). Areas under peak curves were considered proportional to the amount of the analyte present in the chromatograph. Peak area measurements were obtained and individual FAMEs within each sample were determined as a percentage of total fatty acids present.

\section{Statistical analysis}

Individual liver fatty acids are presented as mean percentage \pm standard error (SE) of total fatty acids. One-way analysis of variance and Duncan's post hoc procedures were conducted to determine if statistically significant differences existed among the different dietary groups. Statistical significance was determined at $\mathrm{p}<.05$. Statistical analyses were performed using Statistical Analysis System (SAS) software (SAS, Inc. Cary, NC).

\section{Competing interests}

The authors declare that they have no competing interests.

\section{Authors' contributions}

MJ performed the animal study, liver fatty acid profile analysis, analyzed data, and drafted the manuscript. RDP contributed to the conception and design of the study, supervised the project and edited the manuscript. NLD contributed to the design of the study and edited the manuscript. KRW supervised the fatty acid profile analysis and edited the manuscript. All authors read and approved the final manuscript.

\section{Acknowledgements}

This research was supported by the Tuskegee University College of Agriculture, Environment and Nutrition Sciences. The Alabama Collaboration for Cardiovascular Equality (ACCE) also supported this research. Wendell McElhenney provided invaluable statistical consultation for the research study.

\section{Author details}

${ }^{1}$ College of Agriculture, Environment and Nutrition Science, Tuskegee University, Tuskegee, AL 36088, USA. ²Department of Food and Nutritional Sciences, Tuskegee University, Tuskegee, AL 36088, USA. ${ }^{3}$ Department of Chemistry and Biochemistry, Auburn University, Auburn, AL 36849-5312, USA.

Received: 22 August 2013 Accepted: 19 October 2013

Published: 5 November 2013

\section{References}

1. Lloyd- Jones D, Adams R, Carnethon M, De Simone G, Ferguson TB, Flegal K, Ford E, Furie K, Go A, Greenlund K, et al: Heart disease and stroke statistics-2009 update: a report from the American Heart Association Statistics Committee and Stroke Statistics Subcommittee. Circulation 2009, 119(3):e21-e181.

2. Panagiotakos D, Pitsavos C, Chrysohoou C, Palliou K, Lentzas I, Skoumas I, Stefanadis C: Dietary patterns and 5-year incidence of cardiovascular disease: a multivariate analysis of the ATTICA study. Nutr Metab Cardiovas 2009, 19(4):253-263.

3. Fung TT, Willett WC, Stampfer MJ, Manson JE, Hu FB: Dietary patterns and the risk of coronary heart disease in women. Arch Intern Med 2001, 161(15):1857-1862.

4. Micha R, Wallace S, Mozaffarian D: Red and processed meat consumption and risk of incident coronary heart disease, stroke, and diabetes mellitus: a systematic review and meta-analysis. Circulation 2010, 121(21):2271-2283.

5. Heidemann C, Schulze MB, Franco OH, van Dam RM, Mantzoros CS, Hu FB: Dietary patterns and risk of mortality from cardiovascular disease, cancer, and all causes in a prospective cohort of women. Circulation 2008, 118(3):230-237.

6. Hu F: Plant-based foods and prevention of cardiovascular disease: an overview. Am J Clin Nutr 2003, 78(3):544S-551S.

7. Slavin J: Why whole grains are protective: biological mechanisms. Proc Nutr Soc 2003, 62(1):129-134.

8. Kris-Etherton PM, Taylor DS, Yu-Poth S, Huth P, Moriarty K, Fishell V, Hargrove RL, Zhao G, Etherton TD: Polyunsaturated fatty acids in the food chain in the United States. Am J Clin Nutr 2000, 71(1):179S-188S.

9. Veer $P$, Jansen $M$, Klerk M, Kok F: Fruits and vegetables in the prevention of cancer and cardiovascular disease. Public Health Nutr 2000, 3(1):103-107.

10. Mirmiran P, Noori N, Zavareh M, Azizi F: Fruit and vegetable consumption and risk factors for cardiovascular disease. Metabolism 2009, 58(4):460-468.

11. Dauchet $L$, Amouyel P, Hercberg S, Dallongeville J: Fruit and vegetable consumption and risk of coronary heart disease: a meta-analysis of cohort studies. J Nutr 2006, 136(10):2588-2593.

12. Boffetta P, Couto E, Wichmann J, Ferrari P, Trichopoulos D, Bueno-deMesquita HB, van Duijnhoven FJ, Buchner FL, Key T, Boeing $H$, et al: Fruit and vegetable intake and overall cancer risk in the European Prospective Investigation into Cancer and Nutrition (EPIC). J Natl Cancer Inst 2010, 102(8):529-537.

13. Franke A, Murphy S, Lacey R, Custer L: Tocopherol and tocotrienol levels of foods consumed in Hawaii. J Agric Food Chem 2007, 55(3):769-778.

14. Humphries J, Khachik F: Distribution of lutein, zeaxanthin, and related geometrical isomers in fruit, vegetables, wheat, and pasta products. J Agric Food Chem 2003, 51(5):1322-1327.

15. YouGuo C, ZongJi S, XiaoPing C: Evaluation of free radicals scavenging and immunity-modulatory activities of purslane polysaccharides. Int J Biol Macromol 2009, 45(5):448-452.

16. Chan K, Islam MW, Kamil M, Radhakrishnan R, Zakaria MNM, Habibullah M, Attas A: The analgesic and anti-inflammatory effects of Portulaca oleracea $L$. subsp. sativa (Haw.) Celak. J Ethnopharmacol 2000, 73(3):445-451.

17. Oduro I, Ellis W, Owusu D: Nutritional potential of two leafy vegetables: Moringa oleifera and Ipomoea batatas leaves. Sci Res Essays 2008, 3(2):57-60.

18. Nagai M, Kishimoto Y, lizuka M, Saita E, Suzuki K, Toyozaki M, Murakami K, Sugihara N, Takenaka K, Taguchi C, et al: Effects of sweet potato (Ipomoea 
batatas $\mathrm{L}$.) leaves on LDL oxidation and ROS production. Atherosclerosis Supp/ 2009, 10(2):e1477.

19. Chang WH, Chen CM, Hu SP, Kan NW, Chiu CC, Liu JF: Effect of purple sweet potato leaf consumption on the modulation of the antioxidative status in basketball players during training. Asia Pac J Clin Nutr 2007, 16(3):455-461.

20. Chang WH, Chen CM, Hu SP, Kan NW, Chiu CC, Liu JF: Effect of purple sweet potato leaves consumption on the modulation of the immune response in basketball players during the training period. Asia Pac J Clin Nutr 2007, 16(4):609-615.

21. Chen CM, Li SC, Lin YL, Hsu CY, Shieh MJ, Liu JF: Consumption of purple sweet potato leaves modulates human immune response: T-lymphocyte functions, lytic activity of natural killer cell and antibody production. World J Gastroenterol 2005, 11(37):5777-5781.

22. Chen CM, Lin YL, Chen CY, Hsu CY, Shieh MJ, Liu JF: Consumption of purple sweet potato leaves decreases lipid peroxidation and DNA damage in humans. Asia Pac J Clin Nutr 2008, 17(3):408-414.

23. Agha-Hosseini F, Borhan-Mojabi K, Monsef-Esfahani HR, Mirzaii-Dizgah I, Etemad-Moghadam S, Karagah A: Efficacy of purslane in the treatment of oral lichen planus. Phytother Res 2010, 24(2):240-244.

24. Huang Z, Wang B, Eaves DH, Shikany JM, Pace RD: Total phenolics and antioxidant capacity of indigenous vegetables in the southeast United States: Alabama collaboration for cardiovascular equality project. Int $J$ Food Sci Nutr 2009, 60(2):100-108.

25. Kahlon TS, Chapman MH, Smith GE: In vitro binding of bile acids by spinach, kale, brussels sprouts, broccoli, mustard greens, green bell pepper, cabbage and collards. Food Chem 2007, 100(4):1531-1536.

26. Gong F, Li F, Zhang L, Li J, Zhang Z, Wang G: Hypoglycemic effects of crude polysaccharide from purslane. Int J Mol Sci 2009, 10(3):880-888.

27. Islam I, Shaikh AU, Shahidul IM: Antioxidative and antimutagenic potentials of phytochemicals from Ipomoea batatas (L.). Intl J Cancer Res 2009, 5(3):83-94

28. Kurata R, Adachi M, Yamakawa O, Yoshimoto M: Growth suppression of human cancer cells by polyphenolics from sweetpotato (Ipomoea batatas L.) leaves. J Agric Food Chem 2007, 55(1):185-190.

29. Stevens AM: Evaluating the effects of antioxidant components in novel and traditional vegetable greens on inflammation biomarkers in spontaneously hypertensive rats. M. S. Tuskegee University, Department of Food and Nutritional Sciences; 2011.

30. Medeiros D, Hampton M, Kurtzer K, Parelman M, Al-Tamimi E, Drouillard J: Feeding enriched omega-3 fatty acid beef to rats increases omega-3 fatty acid content of heart and liver membranes and decreases serum vascular cell adhesion molecule-1 and cholesterol levels. Nutr Res 2007, 27(5):295-299.

31. Harris WS, Poston WC, Haddock CK: Tissue $n-6$ and $n-3$ fatty acids and risk for coronary heart disease events. Atherosclerosis 2007, 193(1):1-10.

32. Kabagambe E, Baylin A, Siles X, Campos H: Individual saturated fatty acids and nonfatal acute myocardial infarction in Costa Rica. Eur J Clin Nutr 2003, 57(11):1447-1457.

33. Folch J, Lees M, Sloane S: A simple method for the isolation and purification of total lipides from animal tissues. J Biol Chem 1957, 226(1):497-509.

doi:10.1186/1476-511X-12-168

Cite this article as: Johnson et al:: Diets containing traditional and novel green leafy vegetables improve liver fatty acid profiles of spontaneously hypertensive rats. Lipids in Health and Disease 2013 12:168.

\section{Submit your next manuscript to BioMed Central and take full advantage of:}

- Convenient online submission

- Thorough peer review

- No space constraints or color figure charges

- Immediate publication on acceptance

- Inclusion in PubMed, CAS, Scopus and Google Scholar

- Research which is freely available for redistribution 